\title{
Rogue Access Point Detection in WLAN by Analyzing Network Traffic and Behavior
}

\author{
Shital V Jagtap \\ M.E.(Computer Engg.) \\ D. Y. Patil COE, Akurdi,Pune
}

\author{
K N Honwadkar \\ D. Y. Patil COE, Akurdi, Pune
}

\begin{abstract}
One of the most challenging network security concerns for network administrators is the presence of rogue access points. Rogue access points, if undetected, can be an open door to sensitive information on the network. Many data raiders have taken advantage of the undetected rogue access points to view confidential information. In this paper, we present a rogue access point detection approach. In this approach we are extending the functionality of basic analyzer. It will deeply analyse different properties of WLAN. If required it will calculate statistics and store it in databse. We can use this result to compare next data. Besides analyzing wireless data, some filters are implemented that can be used to identify rogue APs in WLAN. Actually people thinks that analyzer is just common approach but we can use this tool in WLAN in very efficient way ie to reduce time and cost. This topic comes under wireless security
\end{abstract}

The full text of the article is not available in the cache. Kindly refer the IJCA digital library at www.ijcaonline.org for the complete article. In case, you face problems while downloading the full-text, please send a mail to editor at editor@ijcaonline.org 